The question probably arises: is there not a tribal speech of large and predominant people that could be selected as a medium for teaching and literature? I could speak only for this locality. While such a move could be highly desired it would probably meet with stubborn resistance from those large sections that are filled with small dialects and over which the predominant tribes have little or no influence. The Azande or the Mangbeto vernaculars would probably find a footing if they were taught faithfully in all the schools, but this would not settle the difficulties of Lingala on the thousand miles of the big river, and I rather doubt, whether even with long use it would be able to supplant Ituri Ngala. Many of the peoples of the Ituri and Uele are of Sudanic origin rather than Bantu, so we are often informed. This would eliminate this section from amalgamating with the Bangombe, Bangala, Balolo, or the Babangi, and yet Lingala in its various forms holds sway over both regions.

(Communicated by the REV. J. A. BARNEY).

\title{
The Bantu Dramatic Society at Johannesburg.
}

DuRING the past year, an interesting new development has been started in Johannesburg among the members of the Bantu Men's Social Centre, a club for educated Bantu men who, as teachers, mine-clerks, and in other professional occupations, have become more or less detribalized towndwellers. This is the Bantu Dramatic Society which some of the members have founded on their own initiative, with the help of educated Bantu women. In its first programme the Society formulated its aspirations and confessed its faith in the following words: " Although the Society will present European plays from time to time, the aim of the Bantu Dramatic Society is to encourage Bantu playwrights and to develop African dramatic and operatic art. Bantu life is full of great and glorious incidents and figures that would form the basis for first-class drama.'

Actually, the Society elected to make its bow to the Johannesburg public with a European play, viz. Oliver Goldsmith's She Stoops to Conquer. Two performances of this play at Johannesburg were followed by one at Pretoria; and, later in the year, not only was She Stoops to Conquer repeated, but Nongqause, a play in Xosa by Miss M. W. Waters, was added to the Society's répertoire. The author of this play is a white South African lady. The Bantu playwright is still to seek; nor is it at all obvious in what language he will choose to express himself. For, such is still the hold of inter-tribal rivalries and memories of old feuds that a play in any one of the several Bantu languages

area where Ngala is spoken decided to produce one of the Gospels in a unified Ngala, and the book is being printed by the Bible Society. It is hoped that this will help towards the standardization of the language.-EDitor. 
current in South Africa is not at all sure of a welcome from members of tribes speaking some other language. To no small extent does English among educated Bantu bridge the gap of these tribal feelings by serving as a sort of lingua franca, as it does very largely in India.

The selection of She Stoops to Conquer for the Society's inaugural performance was, in part at least, due to the fact that this play had, some months previously, been performed by a visiting English company in His Majesty's Theatre at Johannesburg. This theatre is unique among South African theatres in that it lowers the colour-bar, usually maintained in places of public entertainment for Whites, by admitting Bantu spectators to the gallery when there is room. This gave the Bantu players an opportunity of studying a model of the acting and stage-management with which this play is put on by a White company. In addition, several members of the Johannesburg Amateur Dramatic Society interested themselves in the new venture and assisted the Bantu players with coaching and advice. Professor P. R. Kirby, Head of the Department of Music at the University of the Witwatersrand, and an authority both upon stage-lighting and upon Bantu music and musical instruments, also gave some help. The sympathetic publicity of the local English press resulted in an audience of several hundreds on the 'first night'. Nearly half of those who gathered on the hard, backless benches of the somewhat bleak hall of the Bantu Men's Social Centre were white South Africans in evening dress. If some of them had come to scoff-and found, no doubt, here and there occasions for scoffing-yet the great majority remained to pay a well-deserved tribute to the players for the way in which they surmounted every conceivable handicap, not least the handicap of their own inexperience. Let there be no mistake about it: the handicaps were many, and might well have daunted a less enthusiastic and determined body.

I have already mentioned that the Society had no funds worth mentioning. The pay, in 'civilized' South Africa, even of educated and 'civilized' Natives is wofully low compared with the expense of living. (Even a teacher may receive less than $f_{3}$ per month; and the annual subscription to the Centre is itself only ros. per year.) The members of the Dramatic Society, therefore, could afford only a few shillings each: not enough to hire wigs or period costumes. For wigs, slabs of cotton-wool had to do duty: they lay like white pancakes on dusky heads. The costumes were improvised out of the cheapest materials, in more or less distant semblance of eighteenthcentury fashion and elegance. If we remind ourselves, lastly, that English is not the mother-tongue of Bantu players, and that the forms of ceremonious speech, of gesture and body-posture, of polite manners, in the play are unaccustomed even to twentieth-century Europeans, and more foreign still to South African Natives many of whom had spent their earliest years in a kraal, we shall have added the final touch to the picture of the difficulties which had to be overcome. 
But, overcome they were to a very large extent-indeed, to a much larger extent than might have been expected. Measured by the 'highest' standards of English acting tradition, there were, no doubt, deficiencies and inadequacies in plenty. But to insist on these would be to miss the essential point. For the real question is : Did the play get across the footlights as a living unity, with a spirit of its own? And to this question the answer must be: Yes. By this standard, the Bantu players scored a success which, even for a maiden effort, was more than meritorious.

The secret of their success was their natural aptitude for acting. I want to stress the word ' natural'. Most of the players proved to have a natural gift for acting, not in the sense that they took naturally to the tricks and accomplishments of a traditional technique, but because they played with an unstudied and unpremeditated verve and enjoyment, throwing themselves into their parts and acting them out, free from all self-conscious stiffness, as it were for the fun of the thing. This naturalness showed most, I think, in their laughter. Theirs was not an imitation stage laugh: very often it sounded, and it was, the real thing. They were stiffest and least at their ease in the things they had most definitely required to be taught - the courtly bow, the scraping foot, the flourish of lace handkerchief, the women's curtsies. Curiously enough, it was just this contrast between the somewhat faulty and inadequate externals and the spirit of the story which was none the less conveyed to the audience, that brought home to one the mistake of considering She Stoops to Conquer as mainly a comedy of manners, when it is really a comedy of character, and of universal character to boot. On the whole, the men outshone the women as actors, though one of the latter, off the stage a servant-girl in a White household, had caught from her mistress not a few of a 'lady's ' ways.

Of the performance of Nongqause it is impossible to give an equally favourable account. The main fault, however, must be fairly and squarely laid on the shoulders of the dramatist, not of the actors, though the insufficiency of the stage also made itself far more disturbingly felt. The dramatist has not provided a drama at all, but only a series of scenes, or tableaux, without any dramatic quality, whether taken singly or as a whole. The subject of the play is tragic enough: the story of the famous cattle-killing of 1856 , which was to have been the prelude to a victorious uprising of the Xosa peoples and the sweeping into the sea of the hated White invaders. But it is a subject very difficult to handle, and the authoress possessed none of the qualifications for handling it beyond her excellent command of the Xosa language. Thus, in her hands the story never rises above the level of a jejune, uninspired chronicle.

'Nongqause' is the daughter of Mhlakaza, a witch-doctor (or, as the programme described him, a spirit medium) who persuaded his people to slaughter their cattle and destroy the corn in their granaries, by the prophecy 
that a whirlwind would sweep the White men into the sea; that their ancestors with their kine would thereupon rise from the earth; and that the Bantu would once more be restored to undisputed mastery of South Africa. The outcome of this delusion was sheer tragedy. The prophecy remained unfulfilled : the unhappybelievers died in thousands by starvation; the hated White enemy saved the remnant by organizing soup-kitchens and giving them food.

It would have been a sufficiently difficult technical problem to concentrate this story of mass-hysteria, for stage purposes, into the actions, and the interplay of character, of representative individuals. But, the authoress complicates her tale by trying to point a moral through contrasting the superstition-ridden heathens with the Bible-reading missionary. The first scene discloses the missionary dilating to his wife and the Governor, Sir George Grey, on the belief of the Xosa in the spirits of their ancestors, and it ends with his reading a wearisomely long extract from the Bible, as though the authoress were trying to advertise the Bible, through the medium of the stage, to Native audiences. In a later scene, he harangues, just as lengthily and quite ineffectively, the Chief Sandile and his councillors. In the closing scene, again at length, he and the Governor discourse on the disaster, and the missionary moralizes about the Divinity that shapes our ends. Indeed, the scenes are nearly all speeches, with hardly any action. The Chiefs harangue; the councillors harangue; the witch-doctor harangues; the Governor harangues. Unfortunately, you cannot make an actable drama out of harangues, unless you are a Bernard Shaw.

Probably, the best scene in the play is the one in which the witch-doctor seeks to awaken his daughter (who, though she gives her name to the play, has only a very minor part in its action, and, fortunately, none in the harangues) from deep sleep and to stimulate in her, by the sprinkling on of medicated water and by plentiful incantations, the visions on which his prophecies are based. This glimpse of Native customs, and other glimpses of a less striking kind (e.g. samples of tribal praise songs; the calabash filled with Native beer circulating among the councillors and so on) are among the liveliest bits in a drearily-moving story, and even they are too long drawn out. Very likely, after the Native manner, they are actually even more drawn out in real life, but, none the less, this sort of photographic truth makes poor art on the stage. The very players seemed to get tired of their parts. Incidentally, it was amusing to observe how hard these educated Natives, accustomed to sit on chairs at tables, found it to squat with comfort on the ground, or to rise with grace, let alone with chieftainly dignity. The process of sitting down all too often terminated in a flop; and to stand up again, when hampered by unaccustomed skins or blankets and dangling paraphernalia, required contortions. The Society will be well advised to consign Nongqause to the obscurity of things best forgotten, and wait until some writer with dramatic gifts provides it with a Native play worthy of its powers. 
The further progress of the Society will be watched by all friends of the Natives, and especially of the town-dwelling Natives, with the greatest interest. Under capable and enthusiastic leadership, it may achieve great things for the Johannesburg Native community-providing an outlet for creative self-expression; stimulating and enriching the town-Natives' cultural life; and gaining the sympathetic interest of many Whites who, ordinarily, without positive ill-will against the Native, yet neither know nor care what he feels or does or thinks; who never think of him sufficiently even to ask what life in a White industrial and mining town offers to him beyond an economic pittance, or what he, in turn, can contribute to the life of the town. The performances of the Bantu players may yet build a new bridge across the gap which divides White and Black South Africans into two different worlds. (Communicated by Professor R. F. Alfred Hoernlé, President of the Bantu Men's Social Centre, Johannesburg).

\section{Bantu Language Academies.}

A proposal is being brought by Dr. C. M. Doke before the Inter-University Committee for African Studies, for the setting up of certain language Academies in the Union of South Africa. One of the principal aims of these proposals is to encourage the Bantu people themselves to take a more active part in the development of the languages.

The following is an outline of the proposals :

I. That language Academies be set up, one for each language or languagegroup as decided.

2. That the foundation membership of each such Academy be at least fifty per cent. Bantu.

3. That new members, honorary and active, be appointed to the Academies as a mark of distinction for meritorious work in language or literature.

4. That the terms of reference of the Academies be briefly as follows:

(a) To act as consultative and advisory body on all subsidiary questions of orthography.

(b) To forward dialectal unification and standardization of grammar, vocabulary, idiom, etc., and organize a dialectal survey.

(c) To advise upon the inclusion or exclusion of doubtful or new words, phrases, idioms, grammatical forms, etc., in the language.

(d) To advise upon linguistic terminology.

(e) To choose and propose suitable texts for translation into the vernacular from a foreign language.

(f) To appoint suitable translators or endorse such work already undertaken by individuals.

(g) To approve the content and language of manuscripts submitted, and to recommend such as are approved for assistance in publication. 